\title{
A review of precision technologies in pasture-based dairying systems
}

\author{
L. Shalloo $^{1 \dagger}$, T. Byrne ${ }^{1}$, L. Leso ${ }^{1,2}$, E. Ruelle ${ }^{1}$, K. Starsmore ${ }^{1}$, A. Geoghegan ${ }^{1}$, J. Werner ${ }^{1,3}$, N. O’Leary ${ }^{1,4}$
}

${ }^{1}$ Teagasc, Animal and Grassland Research \& Innovation Centre, Moorepark, Fermoy, Co. Cork, Ireland

${ }^{2}$ University of Florence, Department of Agricultural, Food and Forestry Systems, 50145 Firenze, Italy

${ }^{3}$ Institute for Agricultural Engineering, University of Hohenheim, 70599 Stuttgart, Germany

${ }^{4}$ Hincks Centre for Entrepreneurship Excellence, School of Business, Cork Institute of Technology, Cork, Ireland

Abstract

The promised benefits of precision technologies (PTs) include improved efficiency, quality, animal health and welfare and reduced environmental impacts. To date, PTs (including sensors, algorithms, big data, decisionsupport tools, etc.) have had a relatively modest impact in pasture-based dairying systems in comparison with other agricultural sectors such as arable production. The areas animals roam and graze in pasture-based systems and the associated connectivity challenges may, in part at least, explain the comparatively reduced use of PTs in those systems. Thus, there are very few technologies designed specifically to increase pasture utilisation with the exception of global positioning systems (GPS) and Bluetooth-enabled Plate Meters. Terrestrial and satellitebased spectral analysis of pasture biomass and quality is still in the development phase. Therefore, one of the key drivers of efficiency in pasture-based systems has only been marginally impacted by PTs. In contrast, technological development in the area of fertility and heat detection has been important and offers significant potential value to dairy farmers. In general PTs can be described as good at measurement, data collection and storage but fall down around interpretation and providing useful outputs to end users. As a result, it is unclear if farm management is being sufficiently improved to justify widespread adoption of PTs. A needs-driven development of PTs and decisionsupport tools are required for the succesful integration within agriculture. Further cost/benefit analysis is also required to determine the efficiency of investing in PTs and what, if any, factors affect the variation in the returns.

Keywords

Big data $\bullet$ decision-support $\bullet$ precision technologies $\bullet$ sensors

\section{Introduction}

Agriculture is changing and is challenged by increasing globalisation, fluctuation in food prices, greater societal expectations, environmental constraints and policy changes both at national and international levels. It has been estimated that demand for animal-derived protein may double by 2050 (Henchion et al., 2017). Meeting this demand sustainably will, at a minimum, require producers to maximise production efficiencies while minimising negative environmental impacts, or in other words, developing increasingly resilient and sustainable agricultural systems. Many studies have reported that pasture-based systems of milk production have a distinct advantage over high input systems (Shalloo et al., 2004; Dillon et al., 2005), with grazing systems associated with greater global sustainability, increased product quality (O'Callaghan et al., 2016), improved animal welfare (Wagner et al., 2018), increased labour efficiency (Dillon et al., 2005; O'Brien et al., 2012) and increasing global food security (Laisse et al., 2018) relative to systems of production where the animal is eating feed that could be consumed by humans. Although traditionally prevalent in areas such as the lowland of northwestern Europe, grazing is in competition with maize and renewable energy systems (Taube et al., 2014) despite its strong economic (Dillon et al., 2005) and environmental potential (O'Brien et al., 2012). The potential of grass-based systems is restrained by a lack of expertise and path dependency over the last century which has driven most European farms towards indoor and all year round calving systems. Increasing the efficiency and sustainability of pasture-based (and other) systems is thus desirable to make them even more competitive, especially in areas where the pasture-based system is currently a niche production model. 
In this context, precision technologies (PT) development and application is increasing with "Automation" and "Big Data" now common in industry, society and science. The initial applications of sensor technology were mostly in robotics, defence and industrial production processes (Helwatkar et al., 2014), but this is now expanding to most industries including agriculture. The terms precision agriculture/livestock, smart farming and digital agriculture, and PTs are thus now also familiar. The primary goals of precision livestock farming is to generate reliable data using biosensors, robotics, digital technologies and integrated databases to process it to create value for the farmer, the environment and the animals (Neethirajan et al., 2017). In order to produce added value, the data delivered by PTs (or retrieved from databases) needs to be translated into knowledge to facilitate automation or improved management decisions through using the information in an integrated format to facilitate the decisionmaking process. The integration of Big Data (large data sets that can be treated systematically) is then facilitated by the proliferation of the Internet nationally and the development of cloud-based computing. Therefore, the incorporation of PTs can be viewed as the culmination of a number of processes. The first is to measure the parameter of interest (e.g., pasture growth, quality, grazing cow behaviour) through sensors. The second step is to transfer the sensor data to a hub for integration. This data is generally then converted to useful information through the generation of algorithms. Finally, when this data is integrated with other data/interrogated/ modelled, useful decision-support information can be used to automate processes on farm (e.g., cow drafting, dynamic fertiliser application, etc.) through the provision of advice or a decision back to the end user in an appropriate medium (Rutten et al., 2013). Appropriate data visualisation is key to Precision Livestock Farmer acceptance (Van Hertem et al., 2017). It is only at this point that the data actually has a value for the end user. How information is delivered to the farmer and how the farmer uses this information is integral to the success of any technology (Banhazi et al., 2012) used on farm. In a review of sensors in health management for dairy farms, Rutten et al. (2013) noted that while the measurement part of systems largely functioned, the integration and decision-support elements were inadequate. As a result, while many relevant technologies are currently available, their value to farming systems is not clear (Steeneveld et al., 2015). While PTs in farming promise increased efficiency, improved product quality, reduced environmental impact, and overall improvements in animal health and welfare (Shalloo et al., 2018), much of the benefits have been slow to be realised so far. This has been more pronounced in pasture-based systems (e.g., grass measurement, grassland management, cow location, soil fertility, etc.) in part at least, due to the additional costs of connectivity across large grazing platforms but also partially because of the smaller market size and perceived demand (or lack of) relative to indoor milk production systems. The development of novel PTs to improve the performance of pasture-based systems would be advantageous to improve the productivity of pasture-based dairy farms in the future.

It is crucial that any farm investment strategy will increase the profitability of the farm business or have some social implications, with particular focus on increasing output through increased pasture growth and utilisation (Shalloo et al., 2011). Previous research has reported significant potential for improved efficiency within pasture-based systems in Ireland (Creighton et al., 2011; Kelly et al., 2013). More specifically, technological solutions which can increase the utilisation of pasture and the productivity and fertility of seasonal calving herds are likely to add significant value to pasturebased systems. There is, however, a risk that technologies developed in other contexts will be marketed to farmers in pasture-based systems where their utility is marginal and their efficacy reduced.

At a more aggregate level, PTs could also provide a platform to quantify, in a robust fashion, the sustainability of pasturebased ruminant production systems through integrating existing databases, capturing new data and developing scientifically robust models (Egger-Danner et al., 2007; O'Brien et al., 2014, 2015, 2018). This would aid the achievement of national objectives in consumer protection, continuous quality assurance and would allow claims to be made around various aspects of the production system and food produced from within it (O'Brien et al., 2015, 2018). The objective of this paper is to review big data and smart technologies in pasturebased dairying systems.

\section{Drivers of performance}

How dairy production costs and dairy farm profitability vary by system has previously been investigated (Dillon et al., 2005). As a feed source for livestock, the cost of pasture relative to pasture silage and concentrate has been reported as 1:1.8:2.4, respectively (Finneran et al., 2010). In line with this, the efficiency of pasture-based systems has been found to be positively associated with pasture utilisation, grazing season length and pasture management and negatively associated with supplementation level (Shalloo et al., 2004; Macdonald et al., 2010; Läpple et al., 2012; Ramsbottom et al., 2015; Hanrahan et al., 2018). Grass utilisation is the single greatest driver of profitability and efficiency on pasture-based dairy farms and in particular on those with a spring block calving pattern (Hanrahan et al., 2018).

Across the spectrum of pasture and increased supplementation and total mixed ration (TMR) systems, the optimum calving interval is 365 d (Esslemont et al., 2001). However, the 
relative importance of fertility is comparatively greater in seasonal dairy production systems (Veerkamp et al., 2002; Shalloo et al., 2014). In pasture-based winter milk systems, the quality of ensiled pasture will, for example, be important (Shalloo et al., 2014) and so the development of technologies to help assess and improve the quality and/or reduce the cost of ensiled pasture would be valuable for all systems.

The fertility costs associated with reproductive inefficiency in dairy herds can be broadly divided into five main categories (Shalloo et al., 2014). These costs include the effects associated with:

(1) increased calving interval,

(2) increased culling,

(3) increased labour costs,

(4) increased interventions and,

(5) reduced submission rates.

Synchronising the demand for feed with pasture growth patterns is a key benefit of a spring calving pattern where the peak herd feed demand is matched with peak pasture growth (Shalloo et al., 2007). In other words, a compact calving period in early spring matches the peak intake demands of the cow to spring pasture growth. In pasture-based systems, the negative effect associated with increased calving-interval is magnified as feed supply and herd demand must be aligned. This is the main reason why the economic impact of reproductive inefficiency is even larger in pasture-based systems compared with more intensive systems.

In the long run, if PTs can increase pasture utilisation and cow fertility and or reduce labour requirements while maintaining or reducing costs, they will make a significant contribution to increasing the overall sustainability of pasture-based systems.

\section{Precision technologies in pasture-based dairying systems}

Sensor technologies can be characterised by the measurement method employed and what is being measured. The focus of this review is on what is measured rather than the methods employed to do the measurement within pasture-based systems.

\section{Pasture specific PTs}

Dairy farmers that rely on pasture as their primary feed source and so require accurate real-time measurement of pasture biomass and quality to optimise grazing and nutrition management.

Technology designed specifically to increase pasture utilisation is currently relatively rare. With other crops such as maize and soybean, sensors now routinely being placed in fields measuring the microclimate, spectral characteristics and small-scale differences in soil fertility to help improve crop management and productivity (Wolfert et al., 2017). Sensors developed with a focus on improving pasture growth are still in development and as of yet not commercially available.

Examples of PTs that enable increased pasture utilisation include digitally enabled rising plate meters (grass measurement tools) which streamline and automate aspects of collecting data required to generate pasture budgets (French et al., 2015). These have an added benefit in that the skill and experience required is much less than when compared to visual assessments. Given the importance of measurement in managing and increasing pasture utilisation, plate meters can offer significant benefits for relatively modest investment on a farm. Grass yield data can be combined with global positioning systems (GPS) information and a smartphone in order to be sent to an app or server to calculate on farm pasture availability (French et al., 2015). Another approach is to measure the height of the pasture canopy without a plate resting on the pasture but this is less sensitive to pasture density and so less sensitive to biomass. Distance measurement in both plate and canopy height is usually done via an ultrasonic sensors which measure the height of the canopy itself or of a plate resting on the canopy (Moeckel et al., 2017). While plate meter approaches provide a good estimate of biomass, to assess pasture quality, spectral analysis is an area promising quality estimates (Sibanda et al., 2016) that are quick and efficient alternatives to lab-based assessments.

$\mathrm{Be}$ it handheld, drone or satellite-based, there is increasing momentum around spectral approaches (Sibanda et al., 2016). Spectral analysis can be completed with portable, aerial or satellite-based systems and a common approach is to develop particular wavelengths to create indices such as the normalised difference vegetation index (NDVI) which estimates if vegetation is present or not by assessing the ratio of red and near-infrared wavelengths. The challenges include background soil effects, atmospheric effects, grazing impact and heterogeneity of species and variation in pasture growth stages/proportion of senescent material in the canopy which disproportionately influence spectral data (Moeckel et al., 2017). Most studies have focussed on measuring pastureland biomass in tropical savannahs via remote satellite sensing with less focus on temperate pasturelands (Moeckel et al., 2017). Moeckel et al. (2017) reported combining an ultrasonic sensor with handheld hyperspectral sensor data and satellite-derived spectral data to measure canopy height. They found that the best predictions of biomass were early in the grazing season when pastures were more homogenous. As the grazing season continued issues such as pasture refusal post grazing resulted in variability in the sensor outputs which could not be accounted for when predicting biomass. The $R^{2}$ values achieved with biomass, however, indicate that further 
development is required before practical applications in pastureland management are possible (maximum $R^{2}=0.52$ ). Askari et al. (2019) used an unmanned aerial vehicle (UAV) to gather spectral data to assess pasture quality and achieved an $R^{2}$ of between 0.77 and 0.83 relative to chemical analysis. There has been some progress using satellite data to estimate pasture biomass using synthetic-aperture radar. One study of Irish pasture found that grass biomass could be predicted with an $R^{2}$ of up to 0.75 based on this approach (Ali et al., 2017). However, predictions with that level of accuracy were only achieved periodically when weather conditions were clear. Highly coherent paddocks tended to have low biomass after mowing. Variables such as wind flattening tall grass and grazing or mowing thus complicated the interpretation of the satellite data, especially as biomass increased.

\section{Cow behaviour and status PTs}

Cow behaviour such as movement, location, rumination and resting are of importance for herd management, most notably for heat detection. Several different approaches have been developed to measure various cow behaviours. Some systems use three-dimensional/two-dimensional (3D/2D) cameras in line with machine vision (Nasirahmadi et al., 2017), digital micro-electronics (Beauchemin et al., 1989; Rutter et al., 1997) or pressure sensors to detect jaw movements (Zehner et al., 2017). Büchel \& Sundrum (2014) showed that jaw movements are indicative of feeding behaviour.

Accelerometers are another common sensor on cows and can measure behaviours such as feeding and rumination. The position of those systems on a cow varies with head-, neck-, ear- and leg-mounted devices available (Bikker et al., 2014; Borchers et al., 2016). Accelerometers, usually attached to the animal's legs, can be used to measure locomotion activity (e.g. RumiWatch pedometer, ITIN + $\mathrm{HOCH}$, Fütterungstechnik, Switzerland [Alsaaod et al., 2015] or IceTag pedometer, Northampton, UK [Ungar et al., 2017]). These measurements can give an insight into different events (e.g. heat, health, behaviour, etc.) as increased activity can be associated with oestrus events. Other technologies for heat detection are mounting activity sensors including tail paint, scratch cards, KaMaRs (KaMaR) and HeatWatch (CowChips) (Holman et al., 2011).

As feeding behaviour differs when cows are grazing, the sensors which accurately measure feeding behaviour indoors are unlikely to be as effective with grazing cows without the development of algorithms for grass-based systems, thus sensors may require adaption and recalibration for grazing cows. The research-based noseband sensor RumiWatch is capable of measuring detailed grazing behaviour such as rumination chews and grazing bites as well as rumination and grazing times (Werner et al., 2017a). Most commercial sensors used on farms for measuring grazing behaviour use an accelerometer around the neck (e.g. Heattime ${ }^{\circledR}$; SCR Engineers, Netanya, Israel [Molfino et al., 2017] or MooMonitor+; Dairymaster, Tralee, Ireland [Werner et al., $2017 \mathrm{~b}]$ ), with some of these technologies showing extremely high levels of accuracy $\left(R^{2}>0.90\right)$ (e.g. Moo Monitor).

Another aspect of interest is real-time cow localisation which might be of particular interest in pasture-based systems. There are already a number of techniques to determine animal position indoors. One such system is the Smartbow ear tag (Smartbow $\mathrm{GmbH}$, Weibern, Austria) which has been shown to have reasonable accuracy (within $2.93 \mathrm{~m} \mathrm{95 \%}$ of the time) in determining cow location indoors (Wolfger et al., 2017). Smartbow works by triangulating the location of cow worn ear tags with low-frequency signals which are detected by multiple receivers in the barn allowing triangulation. It is also possible to localize animals via ultra-wideband technology (e.g. CowView; GEA Farm Technologies $\mathrm{GmbH}$, Bönen, Germany [Tullo et al., 2016]). In pasture-based systems, the accurate measurement of the animal's position used to be limited to GPS-based tracking systems (Williams et al., 2016), but other approaches that are less burdensome on batteries are being developed that generally use a combination of approaches.

Health management can be improved by automated detection of dairy cow lameness with sensor technologies. This is particularly relevant in larger pasture-based dairy farms where cows may have to walk long distances between the milking parlour and pasture. There are different approaches, such as a system attached to the cow, mostly pedometers (e.g. IceTag3D ${ }^{\mathrm{Tm}}$; IceRobotics, Edinburgh, UK), walkover systems (e.g. StepMetrix ${ }^{\circledR}$; BouMatic, Madison, WI, USA) and camera systems (Viazzi et al., 2014). Van De Gucht et al. (2017) found in a survey that a sensor attached to the cow was preferred by the end users, followed by a walkover system and a camera system. Some studies already demonstrate positive results for automated lameness detection, but in many cases, the animal must be critically lame to be detected. Beer et al. (2016) showed that it is feasible to differentiate lame cows (>2.5 locomotion score) from non-lame cows with data gathered by a pedometer (RumiWatch). One company has made a leg mounted accelerometer commercially available to detect lameness (IceRobotics, 2017).

\section{Milk sensors}

To date, electrical conductivity and changes in milk colour are the most common indicators for in-line monitoring of udder health. Electrodes are inexpensive and can easily be incorporated inline. There is, however, relatively large variation in sensitivity and specificity. This may be explained by the strong influence of, for example, milk fraction, milk viscosity, temperature, and technical conditions on the measured result, which underlines the necessity for a clear measurement procedure and sensor calibration (Brandt et al., 2010). It is possible to measure 
milk quality parameters such as fat, protein, lactose and milk urea nitrogen contents among others based on in-line sensors. With this data, it is possible to assess the energy and protein supply cows are receiving as well as metabolic imbalances which are major health and welfare concerns in dairy cows and could facilitate improved utilisation of pasture. These milk quality parameters can be accurately measured (milk fat, $R^{2}=0.95$; milk lactose, $R^{2}=0.83$; milk protein, $R^{2}=0.72$; SCC, $R^{2}=0.68$ ) by a near-infrared spectroscopic sensing system (Kawasaki et al., 2008) or additionally with optical methods, biosensors or sensor arrays. The accuracy of the sensor is generally a function of the sensor cost. An example of a commercially available product to determine milk progesterone concentration is the DeLaval Herd Navigator, Tumba, Sweden. The system is able to measure lactate dehydrogenase for detection of (subclinical) mastitis, milk urea to assess the efficiency of protein feed rations and $\beta$-hydroxybutyrate to indicate (subclinical) ketosis and/or secondary metabolic disorders (Dobson, 2016).

\section{Data aggregation and application}

A database is a structured set of records held in a computer that is accessible in various ways. Databases come in many different types and structures and a full discussion of this is beyond the scope of this review. This section will discuss the current types of databases that exist in agriculture today, what they do and how they are linked. There are vast quantities of data collected and stored across a whole range of different aspects of agriculture. Most of this data resides in databases specifically designed to facilitate one form of functionality (e.g. regulation, disease epidemiology, sustainability, etc.). While that data fulfils its original purpose, linking it with other data collected for other purposes could dramatically increase the value of the data, for example, sustainability assessment (O'Brien et al., 2014) or verification of an Irish grass-fed number (O'Brien et al., 2018). Examples may include the use of animal identification information to help populate sustainability models or the use of activity data as an animal welfare indicator. Some databases are designed to monitor commercial farm data and in general, are designed to fulfil a specific farm business requirement. The development of the Internet allows these databases to be stored remotely and linked with other databases.

\section{From data to information}

Raw data is generally of little use to users so the processing and summarising of data is a key aspect of PTs and these processes are generally completed by algorithms (for review, see Valletta et al., 2017). At its most basic level, algorithms can generate coefficients that can then be used to report metrics (e.g. changes in steps taken per day). Building on this and including models, automated inferences are made based on the data. This could, for example, include predicting if a cow is in oestrus or not by drawing upon cow history (e.g. calving date). At a more developed stage, a recommendation to breed or not could be made taking into account factors such as cow waiting period since calving and if a cow has been identified for culling. The sire to be used might also be suggested taking into account available genetic information or breeding goals (e.g. older cows served for beef calves and younger cows served sexed semen to produce more high genetic merits heifer calves). Ultimately an algorithm could partially automate the process by informing the artificial insemination technician of the cow to be served and the sire to use without the farmer's active input.

\section{Interoperability and linkages}

Large quantities of data are generated on farms, stored locally or aggregated by government agencies and companies. In most cases, those databases were developed with limited applications in mind. However, there is a magnitude of potential uses for the data (e.g. milking machine companies sharing data with the genetic improvement organisations around milking speed). A key barrier is aligning the huge incentives for all stakeholders (especially farmers) involved to deliver benefits. Data generated by machinery is generally stored locally and only aggregated by the machinery manufacturer. Integration with other manufacturers' systems and agencies databases is the exception. Data formats and protocols are not standardised and consequently, data measuring the same thing from different systems will not be interchangeable. Sometimes data formats are deliberately protected inhibiting access to the data by third parties. This has resulted in the potential of much of the collected data not being harnessed.

The ability of a sensor or system to work with other in-situ technologies such as ID or drafting gate systems is often crucial to making them viable investments. Collaboration, protocols for interoperability, data formatting standards, open source and open data approaches may be required to realise the full potential of PTs. To improve linkages between databases, there is a requirement to understand the design of existing databases including the database platform and infrastructure. The focus should centre on strategies to develop linkages between different databases. This process should identify issues around data integration and ensure that any future developments in data collection can be undertaken using a standard methodology. The integration of data across relevant databases adds value to the analysis that may be completed as not all the pertinent data resides in a unique database. For example, with every milk collection from a farm, there is an array of data collated (milk temperature, volume and time). Regularly, samples are taken for milk composition 
and milk hygiene and quality characteristics. Some of this data can now be used for management purposes in relation animal health or feeding strategies.

Overcoming the barriers and challenges associated with data and intellectual property protection will be crucial. The challenges include data interoperability, sharing/access, proprietary systems and intellectual property concerns. In response to these challenges, major vendors have responded by creating company-specific ecosystems with good intracompany interoperability. This approach includes bundling/cross-selling of products.

\section{Pastureland management databases}

One such example in the area of pastureland research is PastureBase Ireland (PBI) (Hanrahan et al., 2017). It builds on the concept of citizen science (Conrad \& Hilchey, 2011). Citizen science has proved highly successful in the past in many countries, forming the bedrock of biological recording in various large research projects particularly in ecology and environmental sciences. In the case of PBI, pastureland farmers are the citizen scientists collecting the pastureland data which is the data fuelling a new research program. This function is being achieved through the creation of discussion forums within the PBI system which allows for the roll-out of research and technology initiatives more easily, increasing farmer engagement.

\section{Soil fertility}

Data regarding fertiliser use on farm is generally stored with the merchant where the fertiliser is purchased. Protection of this data is important for many farmers and generally, they are unwilling to share it, harbouring concerns that any disclosure of this data might be used against them (e.g. nitrates regulations, land values). The potential benefits of centrally collecting and storing that data for sustainability assessments or at individual paddock levels to determine fertiliser response functions is significant. Ideally, if the farmer uses an app linked to a smartphone to record fertiliser information (spreading dates, quantities) this information can be automatically integrated with the pastureland database like PBI. This simplifies recording and improves the utility of the data for the farmer.

\section{Animal genetics and health}

Use of veterinary medicines (especially antibiotics) is regulated in most countries with the recording of information regarding diagnosis and treatments being a common requirement. The quantity and type of medicines administered to individual cows could potentially be stored in a central database. However, in most countries, while this information has been systematically recorded on paper, it generally has not been recorded electronically and has not been collated centrally
(Egger-Danner et al., 2007, 2012). One example of a country where a significant effort has been put into standardising and aggregating animal health data relating to dairy cows is Austria. In Austria, the recording of animal health treatments was made a legal requirement in 2002 but the form and coding of this recording were not standardised or aggregated (EggerDanner et al., 2007, 2012).

In relation to animal genetics, there are a number of databases that are critical to increasing herd genetic merit (e.g. International Committee for Animal Recording Interbull database; Irish Cattle Breeding Federation Database). Such data can be collected by public companies or associations (as is done in Ireland) but also by private genetic companies. Information regarding animal performance including milk yield, fertility, longevity, animal health, administered treatments, calving, etc. is routinely recorded. PTs offer huge potential to inform breeding programmes through the automated collection of phenotypic traits such as activity and behaviour, which may be of economic value to select for, within a breeding programme. An example might include monitoring activity data that is collected by devices on individual animals as well as diagnoses of illness or heat events. Many of the traits that these devices collect information on are heritable traits, and it makes practical sense to record to improve future breeding programmes.

\section{Farm decision-support and automation}

The primary objective of using a PT is to inform humans or facilitate automated/improved decision-making on farm. In many cases, human discernment and knowledge cannot be substituted by machines, so machine autonomous decisionmaking is not always possible. PTs can be categorised by the number of stages of decision-making automated for the farmer. Rutten et al. (2013) described four stages of decision-making as a way to characterise how PTs integrate into decisionmaking on farms. In many circumstances, automated decisions may be desirable where the operator's decisions may not practically be able to fully consider and interpret the data, and/ or automation saves the farmer time or labour. As the quantities and types of data available in addition to the multiplicity of automated decision-implementation methods develop, this will become more relevant. In systems that rely on the operator to make and implement decisions, information is made available to them via an interface, report or notification. The format and timeliness of how the information is provided effect the subsequent decision-making process. Some systems have algorithms and interfaces developed specifically to support decisions. Others however, only collect and report data and/ or cannot link different data sources inhibiting aggregation of relevant information in one view or report. 


\section{Decision-support systems (DSS)}

To date, literature about decision-making with PTs is sparse; especially regarding pasture-based dairy systems. Robustness of data collected by sensors is still perceived as a priority and thus, most research focusses on sensing accuracy and systems validation. Decision-making remains pivotal to the successful application of PTs because it determines the value of a PT for the farmer (Hostiou et al., 2017). In recent years, a few significant PTs have become available for pasture-based dairy operations, potentially generating a wealth of data regarding pasture, animal health and milk production.

\section{Pasture}

Decision support systems for pasture management are available for farms which utilise pasture as a major source of feed. Such technology facilitates improved pastureland management, delivering tangible benefits in terms of pasture supply, quality and utilisation (Creighton et al., 2011; Hanrahan et al., 2017) and ultimately profitability (Shalloo et al., 2011). Pasture management tools can include the pasture wedge, pasture budget and the spring and autumn rotation planners. Such tools assist farmers in short- to medium-term pasture management (Macdonald et al., 2010). Some DSS can also use historical pasture growth data to estimate pastureland production capacity and aid long-term management decisions like determining the most suitable stocking rates and plan paddock reseeding, which have been found to be strictly related to the economic performance of pasture-based dairies (Kennedy et al., 2007; Shalloo et al., 2011; McCarthy et al., 2013).

Herbage data such as farm average pasture cover in a given paddock are usually captured manually by the operator using a specific interface. Recent developments in information technology have allowed the development of automated pasture cover sensing (e.g. web-enabled rising plate meter) with a mechanism to upload the data automatically via the cloud (McSweeney et al., 2015). Most DSS for pastureland management now exist in the form of web-based applications. These provide greater flexibility to the user; web-based architecture enables the collation of large quantities of data in central databases which extend DSS functionalities beyond the farm level. Data collected on a wide number of farms can be used to benchmark performance of a single operation, but also for research purposes and policy formulation (Hanrahan et al., 2017).

\section{Health and fertility}

Over the last few years, automatic heat detection systems have become available on pasture-based operations. In some cases, data collected by heat detection systems are integrated with other information regarding the cow (e.g. stage of lactation, fertility status, milk yield, etc.) to provide better decision-support information like whether or when to inseminate a cow or culling decisions (Mottram, 2016). Several DSS have been developed around reproductive management on dairy farms (Giordano et al., 2011; Rutten et al., 2016), and some have focussed on pasture-based production systems (Beukes et al., 2010; Fenlon et al., 2017). These DSS have not been connected to any sensor systems.

\section{Automation}

The clearest example of PTs and automation lie in automatic milking systems (AMS), which utilise data coming from a wide number of sensors to make autonomous decisions. Another example includes automated cow drafting systems using integrated information to autonomously separate cows that need specific attention and which adds significant value to many other sensors installed on farms (Wagner-Storch \& Palmer, 2002). Another autonomous decision-making technology that may find application in pasture-based farms is individualised feeding. The integration of sensor information with in-parlour feeding systems can offer each cow different amounts and types of concentrate according to specific parameters. These kinds of automatic systems are generally known as feed-to-yield systems as individual milk yield is usually the only parameter considered to calculate the amount of feed offered. In pasture-based farms, individualised feeding systems are usually installed in the milking parlour. On AMS, individualised concentrate feeding is standard (Bach \& Cabrera, 2017).

Decision-making deserves further attention in future research as it is key to maximise the benefits of PTs (Rutten et al., 2013). As new and improved PTs are developed, there is a growing need to foster the process of integration of information as it forms the base for sound decision-making. The employment of an open and standardised data format to enable data exchange among PTs is therefore strongly desirable. Advances in the fields of data analytics and computer modelling are expected to facilitate robust analysis systems capable of processing data from several sources. Improvements in DSS and autonomous systems are also expected.

\section{Economics of investment in precision-based technologies}

Although PTs have been widely recognised as a potential route to improve productivity and sustainability of animal husbandry, acceptance and diffusion of such technologies in pasture-based dairy production systems has been limited. Pasture-based farms are known to be low input systems 
where investments need to be carefully evaluated in order to maintain low costs of production. Uncertainty of the cost/benetits of some PTs is likely to be one factor limiting adoption (Neethirajan et al., 2017). In numerous studies, PTs are presented as a way to improve farmers' quality of life by reducing working time and alleviating the burdens associated with farm management tasks. Such benefits often remain theoretical as the adoption of PTs can generate new, intellectually demanding and time-consuming tasks. This is especially true if aspects of the system, such as data presentation and decision-support, are poorly implemented (Hostiou et al., 2017). Another limiting factor for the uptake of PTs on dairy farms is the lack of interoperability (real or perceived) between different data sources and software packages, which restricts integration of information, and thus the value and decision-making capabilities of precision management systems (Aubert et al., 2012).

The efficacy of a novel PT will usually be unclear for a period after it becomes commercially available. Over time, successful tools tend to be validated by independent research organisations. Even if a tool has been shown to be technically effective, for example, accurately detecting oestrus, it may, however, not be economically viable. Potential factors influencing returns from technologies include cost, reliability/ robustness, ease of use, farm circumstances, user's ability and interest. These aspects have rarely been included formally along with assessments of technical efficacy and are crucial to determine the mid to long-term benefits of a PT.

\section{Investment in decision supports}

For dairy farmers, it is difficult to estimate the economic impacts for most PTs in advance of adoption. The risk of expensive technologies delivering poor financial returns to farmers is significant. One of the few studies that investigated this aspect found that PTs did not deliver a discernible return to Dutch dairy farmers between 2008 and 2013 (Steeneveld et al., 2015). They compared three categories of dairy farms, conventional milking systems with no sensor technology, conventional milking systems with sensors, and AMSs. The AMS systems were significantly less profitable than conventional farms with sensors as profit per $100 \mathrm{~kg}$ of milk dropped from $€ 3.86$ to $€ 1.31$. They found that no statistically significant difference in productivity before finance costs could be discerned between conventional systems before and after installing sensor systems, though profit was slightly higher on average after installation (increasing from $€ 5.11$ to $€ 6.16$ ). This indicates, on average, a neutral or very modest return on investment for the average farmer in the study. Similar results were found in a study by Shortall et al. (2016) in relation to AMS technologies within pasture-based systems in Ireland. PT has advanced since that study with, for example, increasing performance of activity sensors (Steeneveld et al., 2017;
Werner et al., 2017a), and advanced techniques such as machine learning applied to activity monitors to add additional value such as the potential to predict/detect calving (Borchers et al., 2017). Returns may have also improved as PTs and knowledge about them improves, and the technology gets cheaper. There may, however, be significant variation in the returns achieved which can be attributed to variation in farms, farmers and technologies invested. Consequently, there will continue to be a proportion of farmers investing in technologies which are not delivering good financial returns. Replicating these findings in a pasture-based dairy system and establishing the reasons for variation in investment returns would add to the literature. Why some farmers benefited financially while others did not, from investing in the Dutch dairy farmer study (Steeneveld et al., 2015), has not been appropriately answered. Farmers are rightfully cautious about technologies until clear information is available on the potential returns. In doing so, they will be likely to overlook specific technologies which offer higher likelihoods of economic benefits.

This information gap is a major issue as the adoption rate of PTs is low (Steeneveld et al., 2017). In light of this, increased knowledge of the drivers of adoption rates can also be used to increase average returns. While the drivers of good returns from technology investment are relatively unknown, there is a wealth of literature on the motivations of farmers to invest in a technology or adopt specific management practices (Garforth et al., 2006; Rehman et al., 2007; Garforth, 2010; Jones et al., 2016).

Traditional decision-support tools generally take traditional forms such as Microsoft Excel, Visual Basic interface Excel, webpages or standalone software programs. They help farmers to improve outcomes or guide difficult decisions around a specific topic, for example, mastitis. The data is generally entered manually by the farmer or the advisor and they do not rely on precision agriculture or big data (Geary et al., 2014). A search of the literature did not uncover any currently available tools focussed specifically on assessing investments in PTs. Developing such tools was previously mentioned as a primary objective in one study (Bewley et al., 2010) and would be of significant value to farmers, advisors and vendors, creating clear information that will assist the decision-making process. It appears that in general, pasture measurement technology and heat detection tools could have a strong economic rationale. More generally, as it is difficult for farmers and researchers alike to discern good and poor investments, cost/benefit analysis of novel technologies is required, in particular, on the areas with greatest potential financial impact (Bewley et al., 2010).

\section{User attributes}

Despite improved information provision, decision-making can still be poorly implemented in part due to variation in 
management capacity to review and interpret the data (Rutten et al., 2013). User attributes may thus have a major impact on the return derived from PTs. Few PTs interpret data and it is rarer still for PTs to automate decision-making (Rutten et al., 2013). For this reason, it is often the case that a technology may only provide information. Whether or not that information is in fact acted upon will likely depend on the user's time availability, attitudes, personality and general ability and understanding in addition to the degree of technology specific training received. O'Leary et al. (2017a, 2017b) assessed the associations between profitability and farm manager attitudes and personality. "Growth mind-set" and "detailed conscious" competencies of dairy farmers were both strongly associated with profitability $\left(R^{2}>0.4\right)$. Those with a growth mind-set believed that their and others' abilities are malleable and are therefore likely to continue learning regularly. A high scorer on "detail conscious" "focusses on detail, likes being methodical, organised and systematic". A low scorer is "unlikely to become preoccupied with detail, less organised and systematic and dislikes tasks involving detail".

\section{Needs-driven precision technology development}

One critique of the current nature of PT in agriculture has been the prevalence of taking of existing mature technology from other sectors (solutions) and then looking for a potential application of these on farm.

Kruger \& Cross (2006) define solution driven design as when:

"The designer focuses on generating solutions, and only gathers information that is needed to further develop a solution. The emphasis lies on generating solutions, and little time is spent on defining the problem, which may be reframed to suit an emerging solution."

Here the solution is more important than the problem or need being solved which only becomes relevant at later stages of the process. Kruger \& Cross (2006) contrast this with problem driven design which they defined as:

"The designer focuses closely on the problem at hand and only uses information and knowledge that is strictly needed to solve the problem. The emphasis lies on defining the problem, and finding a solution as soon as possible."

Need driven (ND) development is a useful paradigm for the development of successful PTs. Indeed, ND is similar to problem driven design but broader in scope and entails developing and delivering technologies to meet clearly defined needs rather trying to repurpose technologies from another context. For example, it includes needs such as increasing labour efficiency which might not be classed as a "problem" per se. We believe the ND approach and focussing on tangible improvements in profitability, sustainability and resilience is key to the success of PTs in sustainable pasturebased systems. We propose that ND technologies are those providing informed and real-time management aids to the farmer. Further, we characterise ND technologies as those delivered in ways that are comprehensible and relevant to the farmer. The third key characteristic of ND technologies is that they contribute data to essential research programmes such a performance evaluation, animal and pasture genetics (Egger-Danner et al., 2007, 2012). Finally, as defining and implementing sustainability remains a major challenge, ND technologies could contribute to a platform to quantify the sustainability of pasture-based ruminant production systems. However, the PTs must be capable of standing on their own by providing justification for their investment directly back to the farmer.

\section{Conclusion}

The integration of sensor data, collated within centralised databases enriched with existing data and analysed for specific end use requirements with outputs provided through appropriate media and in a time appropriate fashion could increase the efficiency of pasture-based farming. A key shortcoming to date in this area is the failure to add value to data collected as the focus has been on accuracy and sensor development and deployment. Designing tools and products with a focus on providing solutions is key to the uptake of technologies into the future. For PTs to realise their potential in agriculture, there is a requirement for the various industry stakeholders to work together to create a consensus regarding the main industry needs and to subsequently develop platforms and infrastructure that can maximise the potential of PTs. The key drivers of efficiency and profitability in pasture-based systems are pasture utilisation and dairy cow fertility. Technologies that advance these components of the business have the greatest chance of delivering a positive return for the end user.

\section{Acknowledgements}

The authors gratefully acknowledge funding provided by Science Foundation Ireland (SFI) through the funded investigator program and the PRECISIONDAIRY Grant Number 13/IA/1977 project and (SFI) and the Department of Agriculture, Food and Marine on behalf of the Government of Ireland under Grant Number [16/RC/3835] - VistaMilk. 


\section{References}

Ali, I., Barrett, B., Cawkwell, F., Green, S., Dwyer, E. and Neumann, M. 2017. Application of repeat-pass TerraSAR-X staring spotlight interferometric coherence to monitor pasture biophysical parameters: limitations and sensitivity analysis. IEEE Journal of Selected Topics in Applied Earth Observations and Remote Sensing 10: 3225-3231.

Alsaaod, M., Niederhauser, J.J., Beer, G., Zehner, N., SchuepbachRegula, G. and Steiner, A. 2015. Development and validation of a novel pedometer algorithm to quantify extended characteristics of the locomotor behavior of dairy cows. Journal of Dairy Science 98: 6236-6242.

Askari, M.S., McCarthy, T., Magee, A. and Murphy, D.J. 2019. Evaluation of grass quality under different soil management scenarios using remote sensing techniques. Remote Sensing 11: 1-23.

Aubert, B.A., Schroeder, A. and Grimaudo, J. 2012. IT as enabler of sustainable farming: an empirical analysis of farmers' adoption decision of precision agriculture technology. Decision Support Systems 54: 510-520.

Bach, A. and Cabrera, V. 2017. Robotic milking: feeding strategies and economic returns. Journal of Dairy Science 100: 7720-7728.

Banhazi, T.M., Lehr, H., Black, J.L., Crabtree, H., Schofield, P., Tscharke, M. and Berckmans, D. 2012. Precision livestock farming: an international review of scientific and commercial aspects. International Journal of Agricultural and Biological Engineering 5: 1-9.

Beauchemin, K.A., Zelin, S., Genner, D. and Buchanan-Smith, J.G. 1989. An automatic system for quantification of eating and ruminating activities of dairy cattle housed in stalls. Journal of Dairy Science 72: 2746-2759.

Beer, G., Alsaaod, M., Starke, A., Schuepbach-Regula, G., Müller, H., Kohler, P. and Steiner, A. 2016. Use of extended characteristics of locomotion and feeding behavior for automated identification of lame dairy cows. PLoS One 11: e0155796.

Beukes, P.C., Burke, C.R., Levy, G. and Tiddy, R.M. 2010. Using a whole farm model to determine the impacts of mating management on the profitability of pasture-based dairy farms. Animal Reproduction Science 121: 46-54.

Bewley, J.M., Boehlje, M.D., Gray, A.W., Hogeveen, H., Kenyon, S.J., Eicher, S.D. and Schutz, M.M. 2010. Assessing the potential value for an automated dairy cattle body condition scoring system through stochastic simulation. Agricultural Finance Review 70: 126-150.

Bikker, J.P., Van Laar, H., Rump, P., Doorenbos, J., Van Meurs, K., Griffioen, G.M. and Dijkstra, J. 2014. Technical note: evaluation of an ear-attached movement sensor to record cow feeding behavior and activity. Journal of Dairy Science 97: 2974-2479.
Borchers, M., Chang, Y., Tsai, I., Wadsworth, B. and Bewley, J. 2016. A validation of technologies monitoring dairy cow feeding, ruminating, and lying behaviors. Journal of Dairy Science 99: 7458-7466.

Borchers, M.R., Chang, Y.M., Proudfoot, K.L., Wadsworth, B.A., Stone, A.E. and Bewley, J.M. 2017. Machine-learning-based calving prediction from activity, lying, and ruminating behaviors in dairy cattle. Journal of Dairy Science 100: 5664-5674.

Brandt, M., Haeussermann, A. and Hartung, E. 2010. Invited review: technical solutions for analysis of milk constituents and abnormal milk. Journal of Dairy Science 93: 427-436.

Büchel, S. and Sundrum, A. 2014. Technical note: evaluation of a new system for measuring feeding behavior of dairy cows. Computers and Electronics in Agriculture 108: 12-16.

Conrad, C.C. and Hilchey, K.G. 2011. A review of citizen science and community-based environmental monitoring: issues and opportunities. Environmental Monitoring and Assessment 176: 273-291.

Creighton, P., Kennedy, E., Shalloo, L., Boland, T.M. and O'Donovan, M. 2011. A survey analysis of grassland dairy farming in Ireland, investigating grassland management, technology adoption and sward renewal. Grass and Forage Science 66: 251-264.

Dillon, P., Roche, J.R., Shalloo, L. and Horan, B. 2005. Optimising financial return from grazing in temperate pastures. In: "Utilisation of grazed grass in temperate animal systems", (ed. J.J. Murphy), Proceedings of a Satellite Workshop of the XXth International Grassland Congress, Wageningen University Press, pages 131-147.

Dobson, H. 2016. Measuring progesterone from the milk line. Veterinary Record 178: 258-259.

Egger-Danner, C., Fuerst-Waltl, B., Olzhacker, W., Janacek, R., Lederer, J., Miesenberger, M., Obritzhauser, W. and Winkler, M. 2007. Establishing a health monitoring system for cattle in Austria. Annual Meeting of the European Federation of Animal Science, Dublin.

Egger-Danner, C., Fuerst-Waltl, B., Obritzhauser, W., Fuerst, C., Schwarzenbacher, H., Grassauer, B., Mayerhofer, M. and Koeck, A. 2012. Recording of direct health traits in Austria-experience report with emphasis on aspects of availability for breeding purposes. Journal of Dairy Science 95: 2765-2777.

Esslemont, R.J., Kossaibati, M.A. and Allcock, J. 2001. Economics of fertility in dairy cows. Recording and evaluation of fertility traits in UK dairy herd. Proceedings of a workshop held in Edinburgh 19th and 20th November 2001, BSAP Occasional Publication, pages 19-29. doi: 10.1017/S0263967X00033565.

Fenlon, C., O'Grady, L., Doherty, M.L., Dunnion, J., Shalloo, L. and Butler, S.T. 2017. The creation and evaluation of a model predicting the probability of conception in seasonal-calving, pasture-based dairy cows. Journal of Dairy Science 100: 5550-5563.

Finneran, E., Crosson, P., Wallace, M., O'Kiely, P., Forristal, P.D. and Shalloo, L. 2010 Simulation modelling of the cost of production and utilizing feeds for ruminants on Irish farms. Journal of Farm Management 14: 95-116. 
French, P., O'Brien, B. and Shalloo, L. 2015. Development and adoption of new technologies to increase the efficiency and sustainability of pasture-based systems. Animal Production Science 55: 931-935.

Garforth, C. 2010. Motivating farmers: insights from social psychology. Annual Meeting - National Mastitis Council, Reading, UK, pages 60-67.

Garforth, C., McKemey, K., Rehman, T., Tranter, R., Cooke, R., Park, J., Dorward, P. and Yates, C. 2006. Farmers' attitudes towards techniques for improving oestrus detection in dairy herds in South West England. Livestock Science 103: 158-168.

Geary, U., Lopez-Villalobos, N., O'Brien, B., Garrick, D.J. and Shalloo, L. 2014. Estimating the impact of somatic cell count on the value of milk utilising parameters obtained from the published literature. Journal of Dairy Science 81: 233-232.

Giordano, J.O., Fricke, P.M., Wiltbank, M.C. and Cabrera, V.E. 2011. An economic decision-making support system for selection of reproductive management programs on dairy farms. Journal of Dairy Science 94: 6216-6232.

Hanrahan, L., Geoghegan, A., O’Donovan, M., Griffith, V., Ruelle, E., Wallace, M. and Shalloo, L. 2017. PastureBase Ireland: a grassland decision support system and national database. Computers and Electronics in Agriculture 136: 193-201.

Hanrahan, L., McHugh, N., Hennessy, T., Moran, B., Kearney, R., Wallace, M. and Shalloo, L. 2018. Factors associated with profitability in pasture-based systems of milk production. Journal of Dairy Science 101: 5474-5485.

Helwatkar, A., Riordan, D. and Walsh, J. 2014. Sensor technology for animal health monitoring. 8th International Conference on Sensing Technology, Liverpool, pages 266-271.

Henchion, M., Hayes, M., Mullen, A., Fenelon, M. and Tiwari, B. 2017. Future protein supply and demand: strategies and factors influencing a sustainable equilibrium. Foods 6: 1-21.

Holman, A., Thompson, J., Routly, J., Cameron, J., Jones, D., GroveWhite, D., Smith, R. and Dobson, H. 2011. Comparison of oestrus detection methods in dairy cattle. Veterinary Record-English Edition 169: 47.

Hostiou, N., Fagon, J., Chauvat, J., Turlot, A., Kling-Eveillard, K., Boivin, X. and Allain, C. 2017. Impact of precision livestock farming on work and human-animal interactions on dairy farms. A Review Base 21: 268-275.

IceRobotics. 2017. COWALERT Lameness Detection Highly Commended. Available online: http://www.icerobotics.com/news/ cowalert-lameness-detection-highly-commended/ [Accessed 28 June 2018]

Jones, P.J., Sok, J., Tranter, R.B., Blanco-Penedo, I., Fall, N., Fourichon, C., Hogeveen, H., Krieger, M.C. and Sundrum, A. 2016. Assessing and understanding European organic dairy farmers' intentions to improve herd health. Preventive Veterinary Medicine 133: 84-96.

Kawasaki, M., Kawamura, S., Tsukahara, M., Morita, S., Komiya, M. and Natsuga, M. 2008. Near-infrared spectroscopic sensing system for on-line milk quality assessment in a milking robot. Computers and Electronics in Agriculture 63: 22-27.
Kelly, E., Shalloo, L., Geary, U., Kinsella, A., Thorne, F. and Wallace, M. 2013. An analysis of the factors associated with technical and scale efficiency of Irish dairy farms. International Journal of Agricultural Management 2: 149-159.

Kennedy, E., O'Donovan, M., Murphy, J.P., Delaby, L. and O'Mara, F.P. 2007. Effect of spring grazing date and stocking rate on sward characteristics and dairy cow production during mid lactation. Journal of Dairy Science 90: 2035-2046.

Kruger, C. and Cross, N. 2006. Solution driven versus problem driven design: strategies and outcomes. Design Studies 27: 527-548.

Laisse, S., Baumont, R., Dusart, L., Gaudré, D., Rouillé, B., Benoit, M., Veysset, P., Rémond, D. and Peyraud, J.L. 2018. The net feed conversion efficiency of livestock: a new approach to assess the contribution of livestock to human feeding. INRA Productions Animales 31: 269-287.

Lapple, D., Hennessy, T. and O' Donovan, M. 2012. Extended grazing: a detailed analysis of Irish dairy farms. Journal of Dairy Science 95: 188-195.

Macdonald, K.A., Glassey, C.B. and Rawnsley, R.P. 2010. The emergence, development and effectiveness of decision rules for pasture-based dairy systems. Proceedings of the 4th Australasian Dairy Science Symposium 2010, DairyNZ, Private Bag 3221, Hamilton, New Zealand, 1 Dairy Centre, Tasmanian Institute of Agricultural Research, University of Tasmania, PO Box 3523, Burnie, Tasmania, Australia.

McCarthy, B., Pierce, K.M., Delaby, L., Brennan, A., Fleming, C. and Horan, B. 2013. The effect of stocking rate and calving date on grass production, utilization and nutritive value of the sward during the grazing season. Grass and Forage Science 68: 364-377.

McSweeney, D., Foley, C., Halton, P. and O'Brien, B. 2015. Calibration of an automated grass height measurement tool equipped with global positioning system to enhance the precision of grass measurement in pasture-based farming systems. Proceedings of the 18th EGF Symposium on "Grassland and forages in high output dairy farming systems". Grassland Science in Europe, volume 20, Wageningen Academic Publishers, Wageningen, the Netherlands, pages 265-267.

Moeckel, T., Safari, H., Reddersen, B., Fricke, T. and Wachendorf, M. 2017. Fusion of ultrasonic and spectral sensor data for improving the estimation of biomass in grasslands with heterogeneous sward structure. Remote Sensing 9: 1-14.

Molfino, J., Clark, C.E.F., Kerrisk, K.L. and García, S.C. 2017. Evaluation of an activity and rumination monitor in dairy cattle grazing two types of forages. Animal Production Science 57 1557-1562.

Mottram, T. 2016. Animal board invited review: precision livestock farming for dairy cows with a focus on oestrus detection. Animal 10: 1575-1584.

Nasirahmadi, A., Edwards, S.A. and Sturm, B. 2017. Implementation of machine vision for detecting behaviour of cattle and pigs. Livestock Science 202: 25-38. 
Neethirajan, S., Tuteja, S.K., Huang, S.T. and Kelton, D. 2017. Recent advancement in biosensors technology for animal and livestock health management. Biosensors and Bioelectronics 98: 398-407.

O'Brien, D., Shalloo, L., Patton, J., Buckley, F., Grainger, C. and Wallace, M. 2012. A life cycle assessment of seasonal grassbased and confinement dairy farms. Agricultural Systems 107: 33-46.

O'Brien, D., Brennan, P., Humphreys, J., Ruane, E. and Shalloo, L. 2014. An appraisal of carbon footprint of milk from commercial grass-based dairy farms in Ireland according to a certified life cycle assessment methodology. International Journal of Life Cycle Assessment 19: 1469-1481.

O'Brien, D., Hennessy, T., Moran, B. and Shalloo, L. 2015. Relating the carbon footprint of milk from Irish dairy farms to economic performance. Journal of Dairy Science 98: 7394-7407.

O'Brien, D., Moran, B. and Shalloo, L. 2018. A national methodology to quantify the diet of a dairy cow. Journal of Dairy Science 101: 8595-8604.

O'Callaghan, T.F., Hennessy, D., McAuliffe, S., Kilcawley, K.N., O'Donovan, M., Dillon, P., Ross, R.P. and Stanton, C. 2016. Effect of pasture versus indoor feeding systems on raw milk composition and quality over an entire lactation. Journal of Dairy Science 99: 9424-9440.

O'Leary, N., Tranter, R. and Bennett, R. 2017a. Farmer attitudes predictive of profitability. Proceedings of the 91st Annual Conference of the Agricultural Economics Society, the Royal Dublin Society in Dublin, Ireland, pages 1-29.

O'Leary, N., Tranter, R. and Bennett, R. 2017b. Farmer Personality and Farm Profitability. Proceedings of the International Farm Management Association Congress 21, Edinburgh, pages 1-17.

Ramsbottom, G., Horan, B., Berry, D.P. and Roche, J.R. 2015. Factors associated with the financial performance of springcalving, pasture-based dairy farms. Journal of Dairy Science $\mathbf{9 8}$ : 3526-3540.

Rehman, T., Mckemey, K., Yates, C., Cooke, R., Garforth, C., Tranter, R., Park, J. and Dorward, P. 2007. Identifying and understanding factors influencing the uptake of new technologies on dairy farms in SW England using the Theory of Reasoned Action. Agricultural Systems 94: 281-293.

Rutten, C.J., Veilthuis, A.G., Steeneveld, W. and Hogeveen, H. 2013. Invited review: sensors to support health management on dairy farms. Journal of Dairy Science 96: 1928-1952.

Rutten, C.J., Steeneveld, W., Vernooij, J.C.M., Huijps, K., Nielen, M. and Hogeveen, H. 2016. A prognostic model to predict the success of artificial insemination in dairy cows based on readily available data. Journal of Dairy Science 99: 6764-6779.

Rutter, S., Champion, R. and Penning, P. 1997. An automatic system to record foraging behaviour in free-ranging ruminants. Applied Animal Behaviour Science 54: 185-195.

Shalloo, L., Dillon, P., Rath, M. and Wallace, M. 2004. Description and validation of the Moorepark Dairy System Model. Journal of Dairy Science 87: 1945-1959.
Shalloo, L., Dillon, P., O'Loughlin, J., Rath, M. and Wallace, M. 2004. Comparison of a pasture-based system of milk production on a high rainfall, heavy clay soil with that on a lower rainfall, free-draining soil. Grass and Forage Science 59: 157-168.

Shalloo, L., O'Donnell, S. and Horan, B. 2007. Profitable dairying in an increased EU milk quota scenario. In: Exploiting the Freedom to Milk. Proceedings of the National Dairy Conference, Lyrath Hotel Kilkenny, Breaffy House Hotel Castlebar, 21-22-Nov-2007, pages 20-44. Available online: https://www.teagasc.ie/media/website/ publications/2007/53_NationalDairyConf2007.pdf.

Shalloo, L., Creighton, P. and O'Donovan, M. 2011. The economics of reseeding on a dairy farm. Irish Journal of Agricultural and Food Research 50: 113-122.

Shalloo, L., Cromie, A. and McHugh, N. 2014. Effect of fertility on the economics of pasture-based dairy systems. Animal 8: 222-231.

Shalloo, L., O'Donovan, M., Leso, L., Werner, J., Ruelle, E., Geoghegan, A., Delaby, L. and O'Leary, N. 2018. Review: Grassbased dairy systems, data and precision technologies. Animal 12, s2: s262-s271.

Shortall, J., Shalloo, L., Foley, C., Sleator, R.D., O Brien, B. 2016. Investment appraisal of automatic milking and conventional milking technologies in a pasture-based dairy system. Journal of Dairy Science 99: 7700-7713.

Sibanda, M., Mutanga, O. and Rouget, M. 2016. Comparing the spectral settings of the new generation broad and narrow band sensors in estimating biomass of native grasses grown under different management practices. GIScience and Remote Sensing 53: 614-633.

Steeneveld, W., Hogeveen, H. and Oude Lansink, A.G.J.M. 2015. Economic consequences of investing in sensor systems on dairy farms. Computers and Electronics in Agriculture 119: 33-39.

Steeneveld, W., Rutten, C.J., Oude Lansink, A. and Hogeveen, H. 2017. Why not investing in sensors is logical for dairy farmers. Proceedings of the European Conference on Precision Livestock Farming'17, Nantes, France, pages 55-64.

Taube, F., Gierus, M., Hermann, A., Loges, R. and Schönbach, P. 2014. Grassland and globalization - challenges for north-west European grass and forage research. Grass Forage Science 69: 2-16.

Tullo, E., Fontana, I., Gottardo, D., Sloth, K.H. and Guarino, M. 2016. Technical note: validation of a commercial system for the continuous and automated monitoring of dairy cow activity. Journal of Dairy Science 99: 7489-7494.

Ungar, E., Nevo, Y., Baram, H. and Arieli, A. 2017. Evaluation of the IceTag leg sensor and its derivative models to predict behaviour, using beef cattle on rangeland. Journal of Neuroscience Methods 300: 127-137. Available online: https://doi.org/10.1016/j. jneumeth.2017.06.001.

Valletta, J.J., Torney, C., Kings, M., Thornton, A. and Madden, J. 2017. Applications of machine learning in animal behaviour studies. Animal Behaviour 124: 203-220.

Van De Gucht, T., Saeys, W., Van Nuffel, A., Pluym, L., Piccart, K., Lauwers, L., Vangeyte, J. and Van Weyenberg, S. 2017. Farmers' 
preferences for automatic lameness-detection systems in dairy cattle. Journal of Dairy Science 100: 5746-5757.

Van Hertem, T., Rooijakkers, L., Berckmans, D., Fernandez Pena, A., Norton, T., Berckmans, D. and Vranken, E. 2017. Appropriate data visualisation is key to Precision Livestock Farming acceptance. Computers and Electronics in Agriculture 138: 1-10.

Veerkamp, R.F., Dillon, P., Kelly, E., Cromie, A.R. and Groen, A.F. 2002. Dairy cattle breeding objectives combining yield, survival and calving interval for pasture-based systems in Ireland under different milk quota scenarios. Livestock Production Science 76: 137-151.

Viazzi, S., Bahr, C., Van Hertem, T., Schlageter-Tello, A., Romanini, C., Halachmi, I., Lokhorst, C. and Berckmans, D. 2014. Comparison of a three-dimensional and two-dimensional camera system for automated measurement of back posture in dairy cows. Computers and Electronics in Agriculture 100: 139-147.

Wagner, K., Brinkmann, J., March, S., Hinterstoißer, P., Warnecke, S., Schüler, M. and Paulsen, H.M. 2018. Impact of daily grazing time on dairy cow welfare-results of the welfare quality ${ }^{\circledR}$ protocol. Animals 8: 1-11.

Wagner-Storch, A.M. and Palmer, R.W. 2002. Animal handling procedures and facilities used by dairy producers to conduct health and reproductive examinations. The Professional Animal Scientist 18: 332-336.

Werner, J., Leso, L., Umstatter, C., Niederhauser, J., Kennedy, E., Geoghegan, A., Shalloo, L., Schick, M. and O'Brien, B. 2017a. Evaluation of the RumiWatchSystem for measuring grazing behaviour of cows. Journal of Neuroscience Methods 300: 138-146.

Werner, J., Leso, L., Umstatter, C., Schick, M. and O'Brien, B. 2017b. Evaluation of precision technologies for measuring cows' behaviour. Grassland Science Europe 22: 82-84.

Williams, M.L., Mac Parthaláin, N., Brewer, P., James, W.P.J. and Rose, M.T. 2016. A novel behavioral model of the pasture-based dairy cow from GPS data using data mining and machine learning techniques. Journal of Dairy Science 99: 2063-2075.

Wolfert, S., Ge, L., Verdouw, C. and Bogaardt, M.J. 2017. Big data in smart farming - a review. Agricultural Systems 153: 69-80.

Wolfger, B., Jones, B.W., Orsel, K. and Bewley, J.M. 2017. Technical note: evaluation of an ear-attached real-time location monitoring system. Journal of Dairy Science 100: 2219-2224.

Zehner, N., Umstätter, C., Niederhauser, J.J. and Schick, M. 2017. System specification and validation of a noseband pressure sensor for measurement of ruminating and eating behavior in stable-fed cows. Computers and Electronics in Agriculture 136: 31-41. 